\title{
Mixtures of substituted pyridinium perchlorates with sulfur- containing organic compounds as inhibitors of acid corrosion of steel
}

\author{
A.G. Berezhnaya,* Gh.A.H. Shayea and V.V. Chernyavina \\ Southern Federal University, ul. Zorge 7, Rostov-on-Don, 344090 Russian Federation \\ *E-mail: ber@sfedu.ru
}

\begin{abstract}
2,4,6-Triphenyl- $N$-(4'-aminophenyl) pyridinium perchlorate (PP1) and 2,4,6-triphenyl- $N$ (2'-bromophenyl)pyridinium perchlorate (PP2), Thiourea (TU), phenylthiourea (PhTU), diphenylthiourea (DPhTU), sodium diethyldithiocarbamate (DEDTC), 2-mercaptobenzothiazole (MBT), and mixtures of pyridinium perchlorates with sulfur compounds were investigated as corrosion inhibitors of steel in a hydrochloric acid solution at temperatures of $20-80^{\circ} \mathrm{C}$. The concentration ranges of substituted pyridinium perchlorates and sulfurcontaining substances were $0.01-0.5$ and $0.1-10 \mathrm{mmol} / 1$, respectively. The coefficients of mutual influence of additives in mixtures, the degree of protection and the coverage of steel surface with inhibitors were estimated. The effect of the investigated additives and their mixtures on the partial reactions of the corrosion process was determined. The mechanism of action of individual additives was determined.
\end{abstract}

Key words: corrosion, low-carbon steel, inhibitor, inhibitor mixtures, substituted pyridinium perchlorates, sulfur-containing organic substances.

Received: July 21, 2017. Published: September 20, 2017.

doi: $\underline{10.17675 / 2305-6894-2017-6-4-2}$

\section{Introduction}

Corrosion protection using inhibitors has proven its effectiveness in various industries. Both individual organic substances and mixtures are used as inhibitors of acid corrosion [1-7]. Substances of different nature contained in formulations, for example, enhance the adsorption capacity of each other, which leads to improved protective properties.

One of the options for obtaining a formulation is to use heterocyclic nitrogen- and sulfur-containing substances as components $[1,5]$. Substituted pyridinium perchlorates have been studied as inhibitors of anodic dissolution of nickel-zinc alloys and zinc [6,7], and the protective ability of thiourea and it is derivatives has also been studied [3].

The purpose of this work is to study the effect of certain substituted pyridinium perchlorates, sulfur-containing organic compounds and their mixtures on the acid corrosion of low-carbon steel, as well as to determine the mechanism of their protective action. 


\section{Experimental}

The objects of the study include low-carbon steel (Steel 3), $0.1 \mathrm{M}$ hydrochloric acid, 2,4,6triphenyl- $N$-(4'-amino-phenyl) pyridinium perchlorate (PP1), 2,4,6-triphenyl- $N-\left(2^{\prime}\right.$ bromophenyl) pyridinium perchlorate (PP2), thiourea (TU), phenylthiourea (PhTU), diphenylthiourea (PhTU), sodium diethyl dithiocarbamate (DEDTC), and 2mercaptobenzothiazole (MBT).

Gravimetric measurements were carried out on low-carbon steel (steel 3) with an area of $5 \mathrm{~cm}^{2}$. Before that, all samples were degreased with ethanol, washed with distilled water and dried with filter paper. After weighing, the samples were placed in the uninhibited and inhibited acid solutions to be tested. They were kept there for a predetermined time, then washed again with distilled water, dried and re-weighed.

The corrosion rate $j$ was calculated by the formula:

$$
j=\Delta m /(t \cdot S),
$$

where $\Delta m$ is the mass loss of the sample (g), $t$ is the experiment time (h), and $S$ is the sample area $\left(\mathrm{m}^{2}\right)$.

The effectiveness of the additives was evaluated by the inhibition factor $\gamma$ and the degree of protection $Z$ :

$$
\begin{gathered}
\gamma=j_{0} / j_{\mathrm{i}} \\
Z=\left(j_{0}-j_{\mathrm{i}}\right) \cdot 100 \% / j_{0}
\end{gathered}
$$

where $j_{0}$ and $j_{\mathrm{i}}$ are the corrosion rate in pure acid and in the presence of additive, respectively.

The mutual influence of additives in the mixtures was estimated by the coefficient of mutual influence $\sigma[4]$ :

$$
\sigma=\frac{\gamma_{\exp }}{\gamma_{1} \cdot \gamma_{2}},
$$

where $\gamma_{\text {exp }}, \gamma_{1}$, and $\gamma_{2}$ are the inhibition coefficients of the mixture and of the first and second components, respectively.

The data for cathodic and anodic polarization curves were collected using a PI-50.01 potentiostat-galvanostat in a three-electrode cell with separated catholyte and anolyte. A platinum wire was used as an auxiliary electrode. Potentials were measured versus a saturated silver chloride reference electrode. The measurements were performed in a step mode, $20 \mathrm{mV}$ per step. The electrode was kept for one minute at each potential $E$, then the current was recorded. Each curve was measured until reproducible results were obtained on the new electrodes in pure acid and at a given inhibitor concentration. Potentials in the work are given in relation to the silver chloride electrode.

Capacitance measurements were carried out in a 2-electrode cell using a P-5021 AC bridge, at frequencies of 1 and $20 \mathrm{kHz}$, with serial connection of capacitance and 
resistance. The auxiliary electrode in the capacitance measurement circuit was a cylindrical platinum electrode. The measured capacitance values were recalculated into a parallel circuit:

$$
C_{\mathrm{p}}=C_{\text {meas }} /\left[1+\left(R_{\text {meas }}-R_{0}\right)^{2} \omega^{2} C_{\text {meas }}^{2}\right],
$$

where $C_{\text {meas }}$ and $R_{\text {meas }}$ are the measured values of capacitance and resistance; $R_{0}$ is the solution resistance determined at a frequency of $f=20 \mathrm{kHz}$; and $\omega=2 \pi f$ is the angular frequency.

The degree of coverage of the electrode surface $(\Theta)$ was calculated by the formula [6]:

$$
\Theta=\left(C_{0}-C_{\mathrm{i}}\right) / C_{0},
$$

where $C_{0}$ and $C_{\mathrm{i}}$ are the capacitance of the double electric layer (CDL) in the acid solution without and with the inhibitor, respectively.

\section{Results and Discussion}

The organic compounds studied as inhibitors are additives of various types: substituted pyridinium perchlorates are cationic additives, 2-mercaptobenzothiazole and thiourea derivatives are molecular additives, and diethyldithiocarbamate is an anionic one. This determines their different adsorption activity.

The presence of chloride ions in the medium promotes the adsorption of organic cations, competes with the adsorption of anions and prevents the adsorption of molecular type additives on the surface of the steel. Molecular and anionic sulfur-containing compounds (S-surfactants) can reduce the corrosion rate of steel by hydrophobizing the surface.

According to the results of gravimetric measurements, all the compounds studied have low protective effects that rise with an increase in their concentration, Tables 1 and 2.

Table 1. Dependence of the inhibition factor and degree of protection of Steel 3 on the concentration of substituted pyridinium perchlorates.

\begin{tabular}{ccccc}
\hline \multirow{2}{*}{$\boldsymbol{c}, \mathbf{m m o l} / \mathbf{l}$} & \multicolumn{2}{c}{$\mathbf{P P 1}$} & \multicolumn{2}{c}{ PP2 } \\
\cline { 2 - 5 } & $\boldsymbol{\gamma}$ & $\boldsymbol{Z , ~ \%}$ & $\boldsymbol{\gamma}$ & $\boldsymbol{Z}, \boldsymbol{\%}$ \\
\hline 0.01 & 3.05 & 67.21 & 2.02 & 50.50 \\
0.05 & 4.25 & 76.47 & 2.5 & 60.00 \\
0.1 & 4.36 & 77.06 & 3.44 & 70.93 \\
0.25 & 8.51 & 88.25 & 4.04 & 75.25 \\
0.5 & 10.46 & 90.44 & 4.99 & 79.96 \\
\hline
\end{tabular}


Table 2. Dependence of the inhibition coefficient of Steel 3 on the concentration of sulfur-containing organic substances.

\begin{tabular}{cccccc}
\hline & \multicolumn{5}{c}{ The $\gamma$ values for additives } \\
\cline { 2 - 6 } C, $\mathbf{~ m m o l} / \mathbf{l}$ & TU & PhTU & DPhTU & DEDTC & MBT \\
\hline 0.1 & 1.3 & 0.98 & 1.1 & 1.54 & 1.69 \\
0.5 & 1.52 & 1.09 & 1.18 & 1.79 & 1.82 \\
1 & 1.86 & 1.18 & 1.29 & 2.86 & 3.56 \\
5 & 2.53 & 1.23 & 1.39 & 3.24 & 5.41 \\
10 & 3.6 & 1.67 & 1.77 & 4.42 & 7.47 \\
\hline
\end{tabular}

As one can see from the data presented, at the same concentrations, substituted pyridinium perchlorates are $2-10$ times more effective than organic compounds containing sulfur, depending on the structure. Among the organic compounds, 2mercaptobenzothiazole and diethyldithiocarbamate are more effective, and thiourea is the most effective among the urea derivatives. Incorporation of phenyl groups into thiourea leads to a decrease in protective properties with respect to the corrosion of low-carbon steel in hydrochloric acid.

The reduction of the corrosion rate of steel in an acidic environment upon addition of inhibitors is mainly associated with the effect of surface blocking, which changes the effective activation energy of the process and alters the structure of the double electrical layer [9]. The dependence of the inhibition coefficients obtained on the concentration of the additives is fairly well linearized in $\lg \gamma-\lg C$ coordinates, which indicates a significant contribution of the blocking effect to their action, Figure 1.

The temperature is a significant factor affecting the speed of the process and the effectiveness of corrosion inhibitors. The temperature affect on the protective effect of the additives studied is presented in Table 3.

Table 3. Dependence of the inhibition coefficient on the nature of the additive and composition of the mixture on temperature.

The $\gamma$ values for individual additives and their mixtures

\begin{tabular}{cccccccc}
$\boldsymbol{t},{ }^{\circ} \mathbf{C}$ & PP1 & PP2 & DPhTU & DEDTC & $\begin{array}{c}\text { PP1 }+ \\
\text { DPhTU }\end{array}$ & $\begin{array}{c}\text { PP2 }+ \\
\text { DPhTU }\end{array}$ & $\begin{array}{c}\text { PP2 }+ \\
\text { DEDTK }\end{array}$ \\
\hline 30 & 1.58 & 1.84 & 3.34 & 1.19 & 2.49 & 1.20 & 3.80 \\
40 & 12.81 & 12.34 & 7.20 & 7.42 & 4.12 & 2.14 & 5.25 \\
60 & 21.64 & 18.94 & 7.35 & 4.40 & 9.90 & 11.17 & 4.95 \\
80 & 24 & 14.89 & 10.8 & 7.17 & 16.78 & 10.15 & 14.88 \\
\hline
\end{tabular}



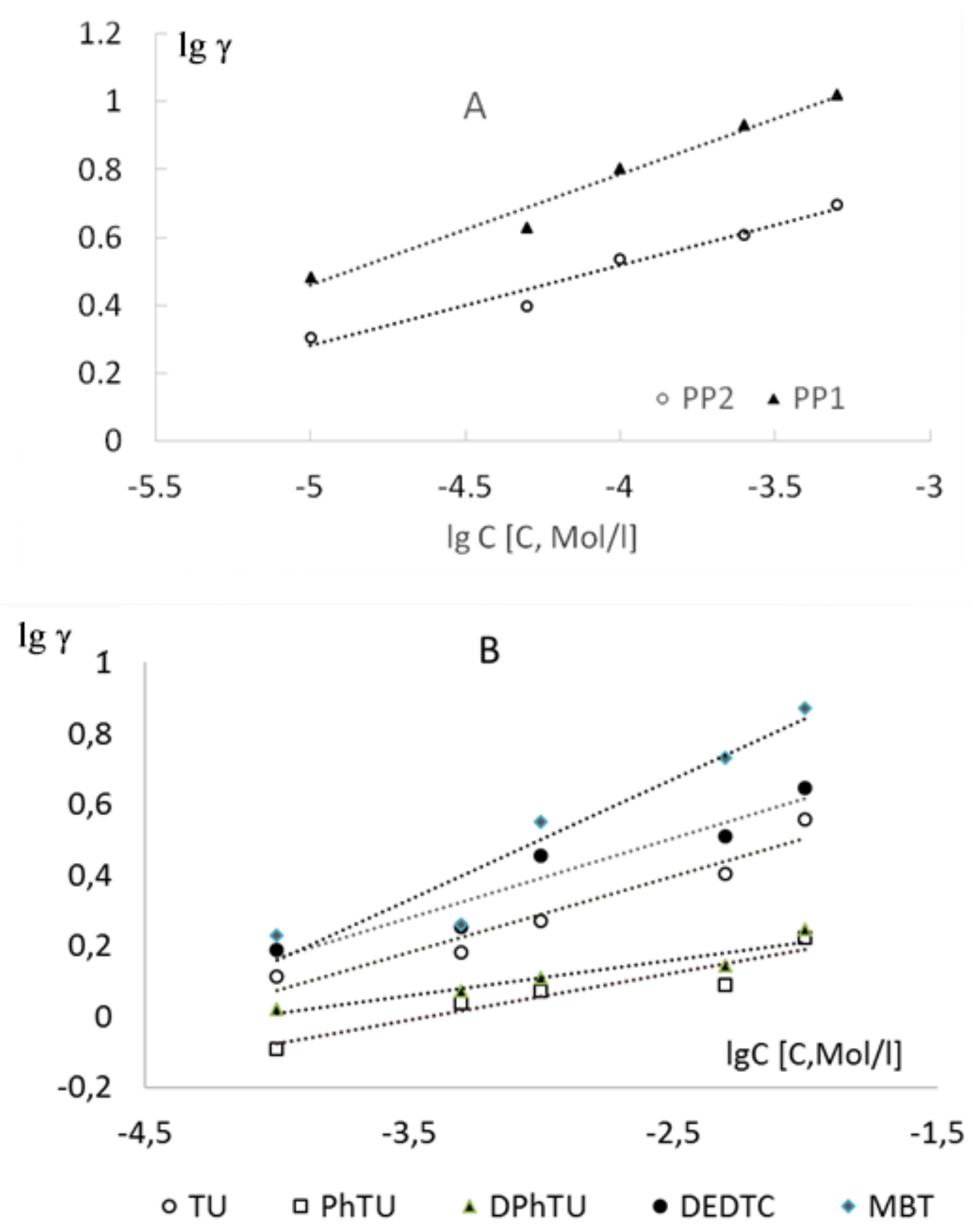

Figure 1. Dependence of the corrosion inhibition coefficient on the concentration of substituted pyridinium perchlorates (A) and sulfur-containing organic substances (B). The abbreviations in the legend are the names of the additives.

An increase in temperature leads to an increase in the corrosion rate and protective effect. The temperature dependence of the corrosion rate is well linearized in the Arrhenius coordinates, which makes it possible to calculate the effective activation energy of the corrosive process in the pure acid and in the presence of additives and mixtures, Figure 2. 

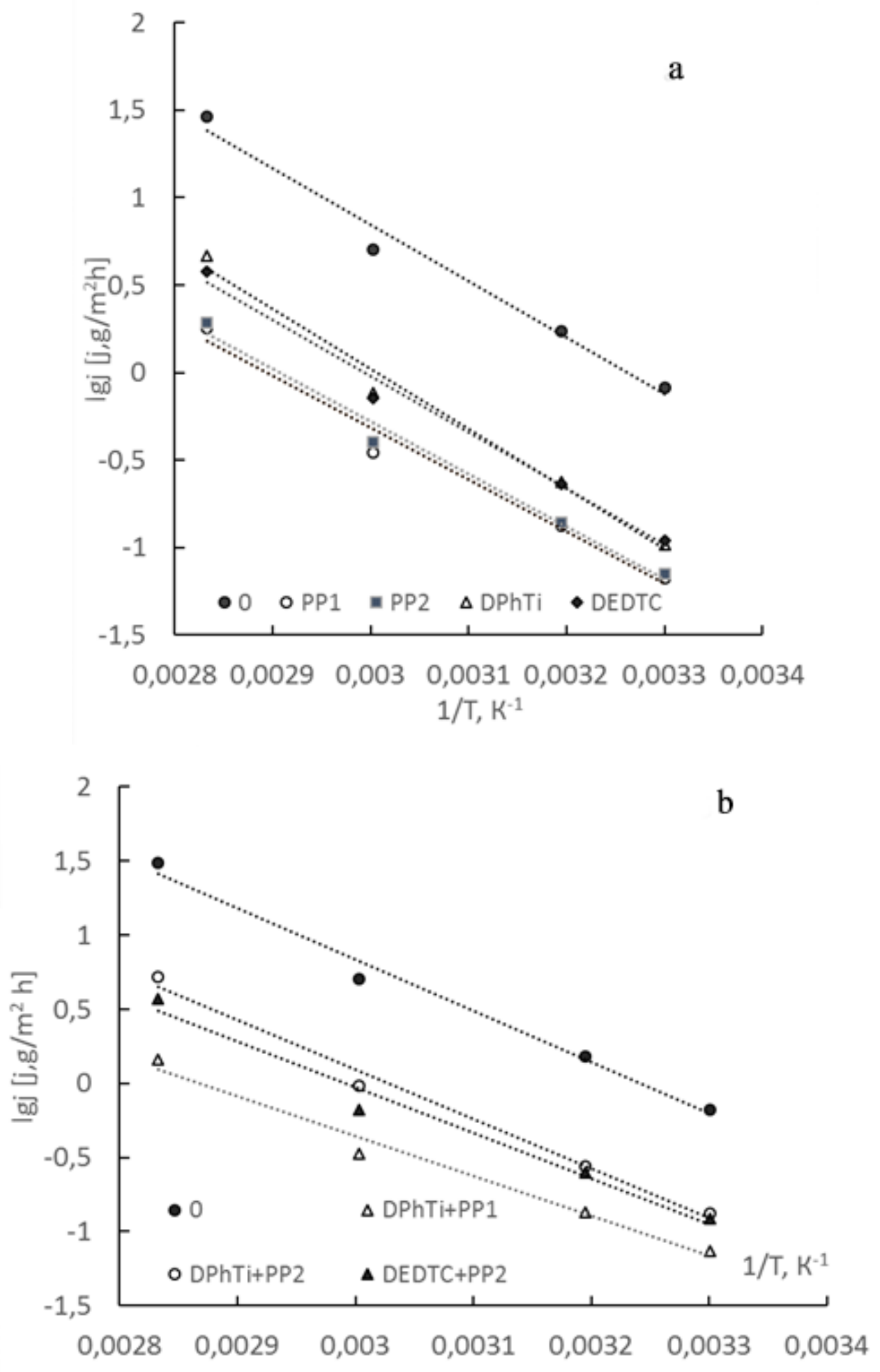

Figure 2. Dependence of corrosion rate on temperature in hydrochloric acid solution without $(0)$ and in the presence of additives and their mixtures.

The calculated effective activation energies are presented in Table 4. 
Table 4. The dependence of the effective activation energy, the degree of protection and the degree of surface coverage on the nature of the additives and mixtures, $C_{\text {add }}=0.1 \mathrm{mmol} / \mathrm{l}$.

\begin{tabular}{ccccccccc}
\hline Parameter & $\mathbf{0}$ & PP1 & PP2 & DPhTU & DEDTC & $\begin{array}{c}\text { PP1 }+ \\
\text { DPhTU }\end{array}$ & $\begin{array}{c}\text { PP2 }+ \\
\text { DPhTU }\end{array}$ & $\begin{array}{c}\text { PP2 }+ \\
\text { DEDTC }\end{array}$ \\
\hline$E_{\text {eff, } \mathrm{kJ} / \mathrm{mol}}$ & 61.5 & 53.6 & 57.4 & 61.5 & 61.3 & 51.4 & 63.8 & 58.8 \\
$\Theta, \%$ & - & 89 & 82 & 20 & 20 & 70 & 93 & 94 \\
$Z, \%$ & - & 77 & 71 & 9 & 33 & 71 & 89 & 83 \\
\hline
\end{tabular}

From the data obtained, it can be seen that individual compounds either do not change the activation energy (DPhTU and DEDTC), or slightly reduce it. The decrease in the effective activation energy in the inhibition process can be associated with the formation of a polymolecular inhibitor film on the steel surface. This leads to a change in the mechanism of the process, or to an increase in the degree of surface coverage with an additive as the temperature increases.

The capacitive measurements carried out show that all the additives studied are sufficiently well adsorbed and block part of the surface, thereby reducing the corrosion rate. The degree of surface coverage $(\Theta)$ by the additives and the degree of steel protection by them at the same concentrations are shown in Table 4 . In most cases, $\Theta>Z$, which can be associated with the formation of a laced additive layer on the steel surface.

In the context of a possible increase in the protective effect of additives, it is advisable to consider the effect of additive mixtures rather than individual substances.

The coefficients of steel corrosion inhibition by mixtures of pyridinium perchlorates with sulfur-containing organic substances are slightly higher than those of individual additives, however, the interaction coefficients of substances in the mixtures are in most cases less than one, Figure 3.

A mutual enhancement of the properties of additives $(\sigma>1)$ is observed only in the mixture of PP1 with diphenylthiourea, as well as in the mixtures of PP2 with diphenylthiourea and sodium diethyldithiocarbamate. The difference between PP2 and PP1 compounds is that in the phenyl radical bound to pyridinium nitrogen, the amino group in the $p$-position is replaced by bromine in an $o$-position. Hence, DPhTU and DEDTC enhance the adsorption of the first compound and do not affect or weaken it in the case of the PP1 compound.

Data of impedance measurements also agree with this, Table 4. The degree of coverage of steel surface with mixtures of the PP2 compound with diphenylthiourea and diethyldithiocarbamate is higher than for the mixture of the PP1 compound with DPhTU.

In terms of the influence on the cathodic and anodic curves, the mixtures have both similar and different features in comparison with individual additives, Figure 4. 


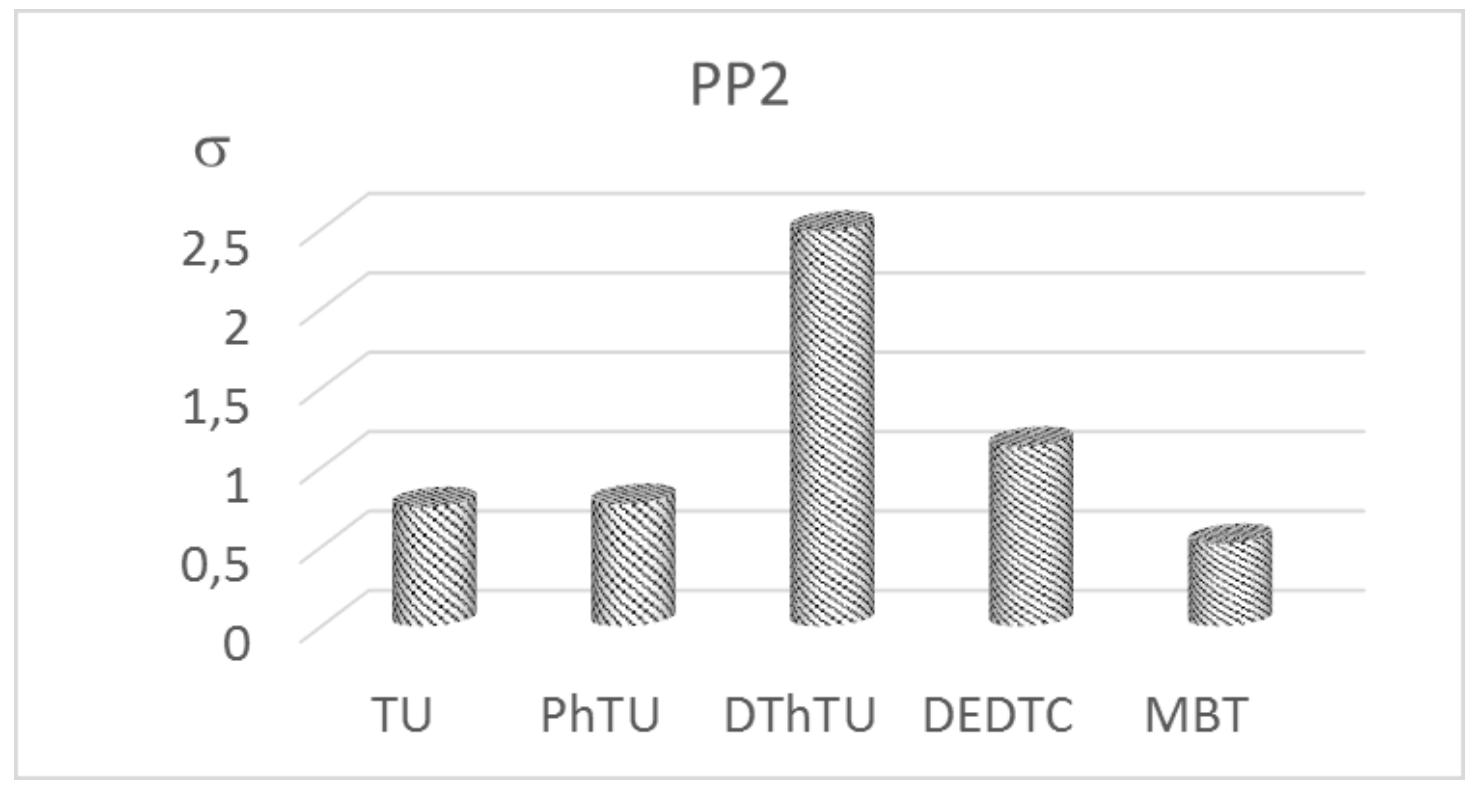

\section{PP1}
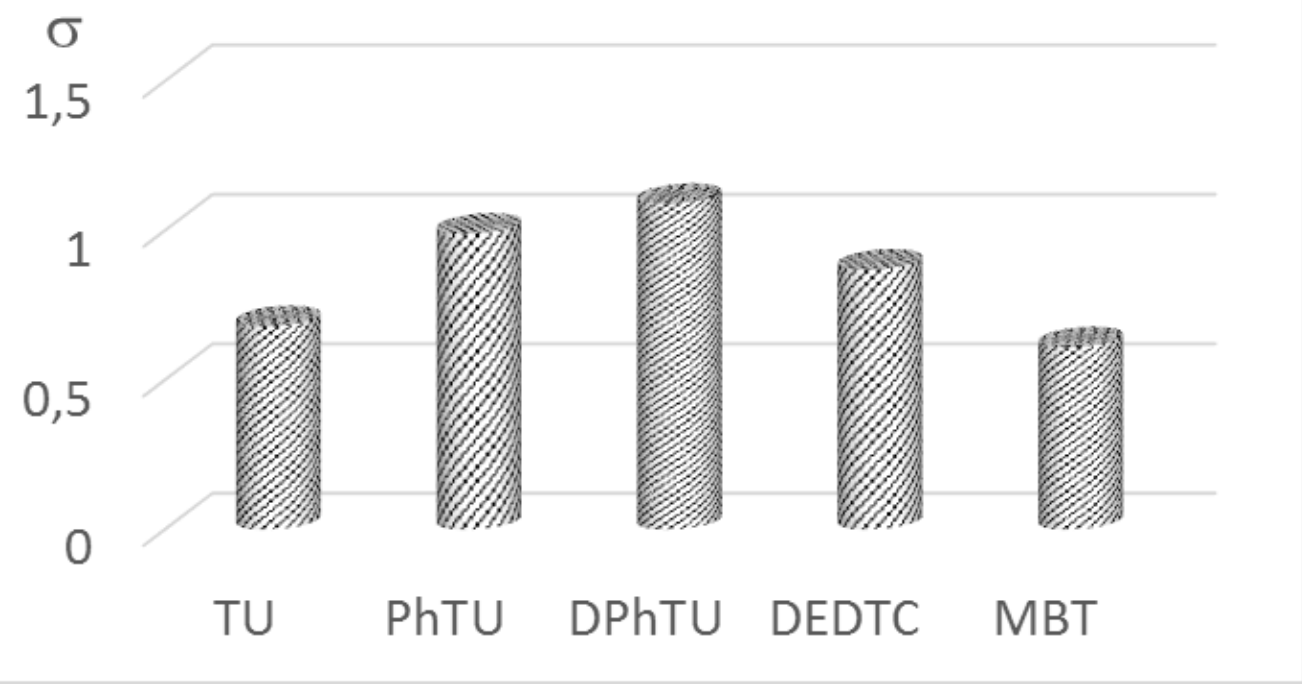

Figure 3. Coefficients of mutual influence of mixtures of PP2 and PP1 with sulfur-containing substances, $C_{\text {add }}=0.1 \mathrm{mmol} / 1$.

The dependence of the inhibition coefficient of partial electrode reactions on $E$ is presented in Table 5. 


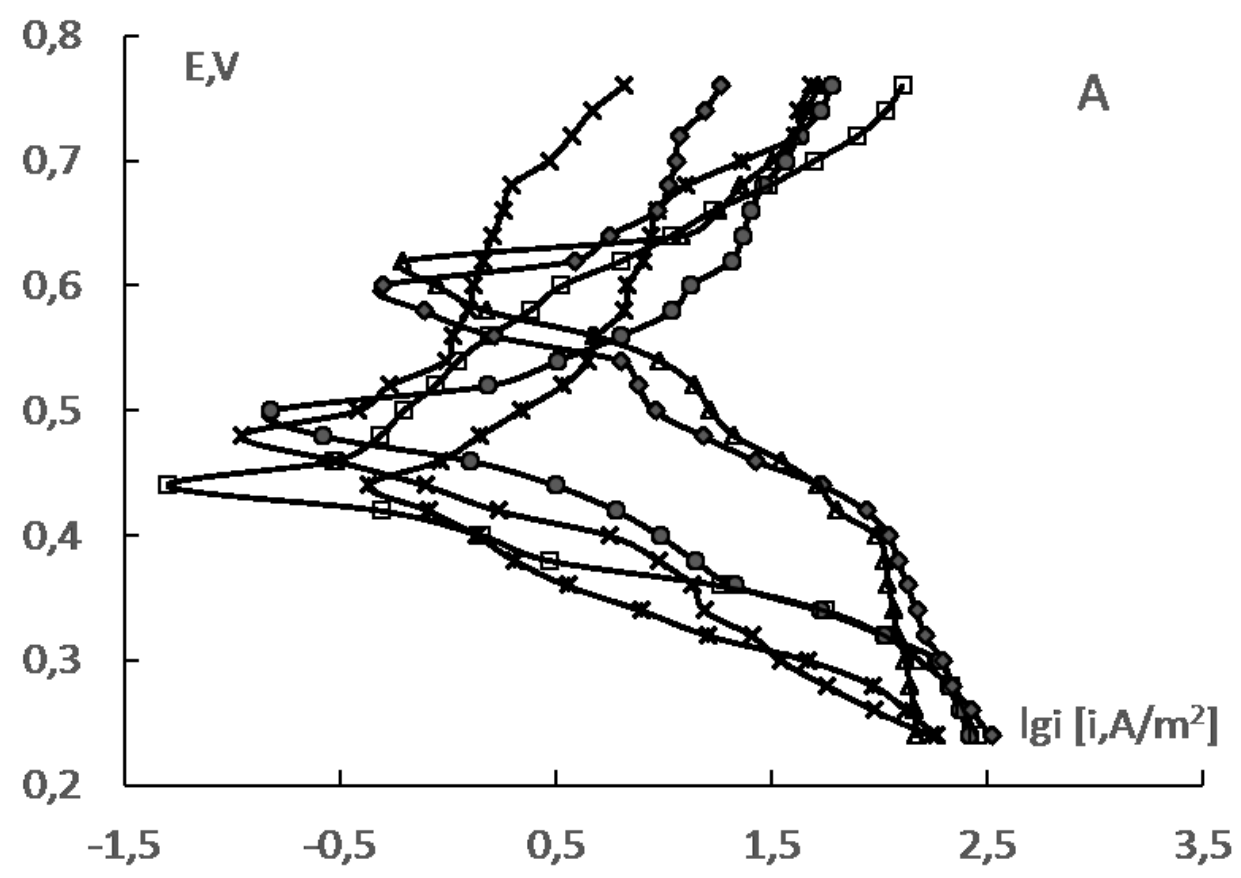

$\multimap 0 \rightarrow-P P 2 \rightarrow D E D T C \multimap P P 1 \rightarrow D P h T U \rightarrow P h T U$

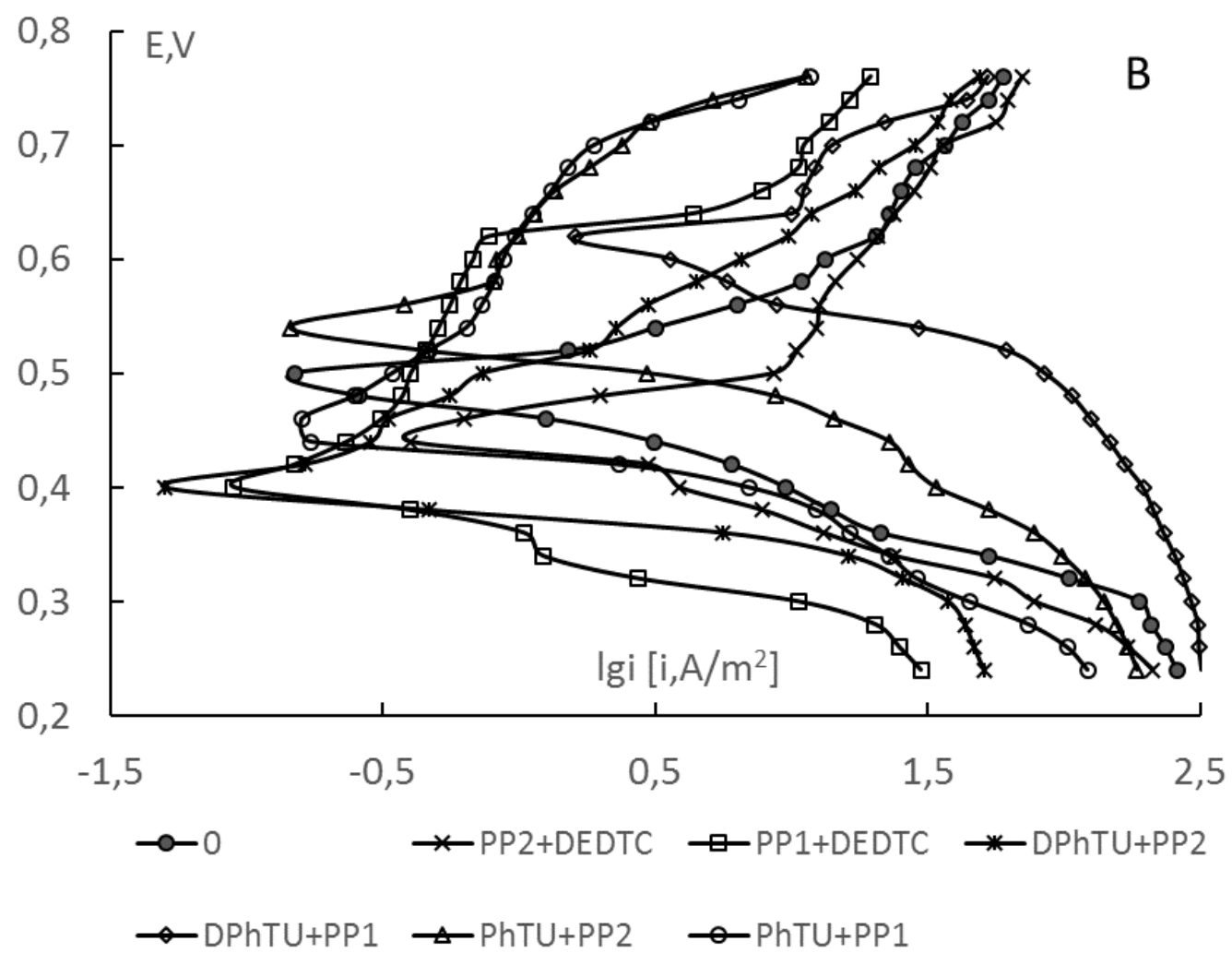

Figure 4. Polarization curves of steel 3 in hydrochloric acid without additives (0), in the presence of individual additives (a) and mixtures (b), $C_{\text {add }}=0.1 \mathrm{mmol} / \mathrm{l}$. 
Table 5. Dependence of the inhibition coefficient on the potential and nature of additives.

\begin{tabular}{cccccc}
\hline & \multicolumn{5}{c}{ The $\gamma$ values for additives } \\
\cline { 2 - 5 } & DEDTC & DPhTU & PhTU & PP1 & PP2 \\
\hline 0.70 & 1.60 & 12.62 & 1.16 & 3.21 & 0.74 \\
0.64 & 2.67 & 14.38 & 1.92 & 4.11 & 2.13 \\
0.54 & 0.73 & 3.29 & 3.37 & 0.5 & 2.9 \\
0.40 & 6.79 & 1.69 & 0.1 & 0.09 & 6.79 \\
0.34 & 6.70 & 3.41 & 0.46 & 0.36 & 1.0 \\
0.30 & 4.07 & 5.43 & 1.44 & 0.96 & 1.23 \\
\hline
\end{tabular}

The observed acceleration of the the anodic reaction by some additives (PP1, PhTU) and of the cathodic reaction by PP2 and DEDTC in limited potential regions is due to a change in the corrosion potential. At the majority of potentials, PP2, DPhTU and DEDTC inhibit both reactions of the corrosion process.

The mixture of PP2 with DEDTC either does not affect the speed of cathodic hydrogen evolution or stimulates it at $E>-0.6 \mathrm{~V}$. At the same time, the corrosion potential increases by $80 \mathrm{mV}$, and the rate of dissolution of steel decreases at all the potentials studied. In the case of the DEDTC + PP1 mixture, a limiting current is observed in the cathodic potential region, and the rate of the anodic reaction decreases more than 10 -fold, Table 6.

Table 6. Dependence of the inhibition coefficient on the potential and composition of the mixture.

\begin{tabular}{ccccccc}
\hline \multirow{2}{*}{, $\mathbf{V}$} & \multicolumn{6}{c}{ Values of $\gamma$ for mixtures } \\
\cline { 2 - 7 } & $\begin{array}{c}\text { DEDTC }+ \\
\text { PP2 }\end{array}$ & $\begin{array}{c}\text { DPhTU }+ \\
\text { PP2 }\end{array}$ & $\begin{array}{c}\text { PhTU }+ \\
\text { PP2 }\end{array}$ & $\begin{array}{c}\text { DEDTC }+ \\
\text { PP1 }\end{array}$ & $\begin{array}{c}\text { DPhTU }+ \\
\text { PP1 }\end{array}$ & $\begin{array}{c}\text { PhTU + } \\
\text { PP1 }\end{array}$ \\
\hline 0.70 & 1.0 & 1.28 & 15.25 & 3.27 & 2.58 & 19.26 \\
0.64 & 0.96 & 1.93 & 20.9 & 5.23 & 2.3 & 20.9 \\
0.54 & 0.26 & 1.39 & 4.98 & 6.4 & 0.11 & 4.98 \\
0.40 & 2.44 & 190 & 0.28 & 105.6 & 0.05 & 1.36 \\
0.34 & 2.23 & 3.26 & 0.54 & 44.1 & 0.21 & 2.31 \\
0.30 & 2.43 & 5.0 & 1.35 & 17.83 & 0.64 & 4.2 \\
\hline
\end{tabular}


Table 6. Dependence of the inhibition coefficient on the potential and composition of the mixture (cont.).

\begin{tabular}{ccccccc}
\hline \multirow{2}{*}{$\boldsymbol{E}, \mathbf{V}$} & \multicolumn{5}{c}{ Values of $\boldsymbol{\sigma}$ for mixtures } \\
\cline { 2 - 7 } & $\begin{array}{c}\text { DEDTC }+ \\
\text { PP2 }\end{array}$ & $\begin{array}{c}\text { DPhTU }+ \\
\text { PP2 }\end{array}$ & $\begin{array}{c}\text { PhTU }+ \\
\text { PP1 }\end{array}$ & $\begin{array}{c}\text { DEDTC }+ \\
\text { PP1 }\end{array}$ & $\begin{array}{c}\text { DPhTU + } \\
\text { PP1 }\end{array}$ & $\begin{array}{c}\text { PhTU + } \\
\text { PP2 }\end{array}$ \\
\hline 0.70 & 0.84 & 0.14 & 0.64 & 0.06 & 5.17 & 17.76 \\
0.64 & 0.17 & 0.06 & 0.48 & 0.04 & 2.63 & 5.11 \\
0.54 & 0.12 & 0.15 & 17.65 & 0.08 & 2.95 & 0.5 \\
0.40 & 0.05 & 4.13 & 172 & 0.33 & 151 & 0.41 \\
0.34 & 0.35 & 1.02 & 18.29 & 0.17 & 13.9 & 1.24 \\
0.30 & 0.49 & 0.75 & 4.56 & 0.12 & 3.04 & 0.76 \\
\hline
\end{tabular}

The opposite picture is observed in mixtures of PP2 and PP1 compounds with diphenylthiourea, Figure 5 . The mixtures significantly and antibatically change the corrosion potential of steel and differ in their effect on the anodic reaction rate. By decreasing the corrosion potential by more than $100 \mathrm{mV}$, the PP1 + DPhTU mixture increases the steel dissolution rate (similarly to the individual PP1). The PP2 + DPhTU mixture slows down the rates of both processes and increases the corrosion potential by $100 \mathrm{mV}$.

Replacement of DPhTU by PhTU in the mixtures inverses the effect on the corrosion potential. In fact, the PP1 + PhTU mixture increases the corrosion potential of steel, whereas the PP2 + PhTU mixture decreases it by approximately $50-60 \mathrm{mV}$. As a result, the PP1 + PhTU mixture inhibits the anodic dissolution of the steel. Mixtures of PP2 and PP2 with phenylthiourea reduce the rate of cathodic hydrogen evolution more strongly than the other mixtures, Table 6.

In most cases, like in the case of corrosion measurements, the additives in the mixtures weaken the effects of each other. In the PhTU + PP1 mixture, irrespective of the potential region, the protective properties of the additives mutually enhance each other. This is also observed in the case of the PP1 + DEDTC mixture, but only in the anodic potential region. A mutual enhancement of the protective properties of PP2 is observed in its mixtures with DPhTU and PhTU in the anodic and cathodic regions, respectively.

\section{Conclusions}

1. Substituted pyridinium perchlorates and the sulfur-containing organic compounds studied are mixed or cathodic type inhibitors, depending on their chemical structure. They reduce the corrosion rate mainly due to their blocking effect.

2. In most mixtures, substituted pyridinium perchlorates and sulfur-containing organic substances weaken the protective effects of each other. 2,4,6-Triphenyl- $N$-(4'-aminophenyl)pyridinium perchlorate and phenylthiourea at $0.1 \mathrm{mM}$ concentration enhance the protective effects of each other in the entire range of potentials studied. 


\section{References}

1. Ya.G. Avdeev and M.V. Tyurina, Korroz.: mater., zashch., 2017, no. 5, 1 (in Russian).

2. Ya.G. Avdeev and Yu.I. Kuznetsov, Russ. Chem. Rev., 2012, 81, no. 12, 1133.

3. R.T. Loto, C.A. Loto and A.P.I. Popoola, J. Mater. Environ. Sci., 2012, 3, no. 5, 885.

4. V.V. Ekilik and O.V. Chikov, Zashch. Met. (Protection of Metals)., 1991, 27, 72 (in Russian).

5. Ya.G. Avdeev and Tyurina M.V., Korroz.: mater., zashch., 2016, no. 2, 7 (in Russian).

6. V.V. Ekilik, E.A. Tugolukova and A.G. Berezhnaya, Zashch. Met. (Protection of Metals)., 2004, 40, no. 2, 149 (in Russian).

7. A.G. Berezhnaya and V.V. Chernyavina, Mezhdunarodnyi zhurnal fundamental'nykh $i$ prikladnykh issledovanii, 2015, no. 12, part 8, 1402 (in Russian).

8. B.B. Damaskin, O.A. Petriy and V.V. Batrakov, Adsorbtsiya organicheskikh soedinenii na elektrodakh (Adsorption of organic compounds on electrodes), Moscow, Nauka, 1968 (in Russian).

9. L.I. Antropov, Formal theory of the action of organic corrosion inhibitors, Zashch. Met. (Protection of Metals)., 1977, 13, no. 4, 387 (in Russian). 